\title{
Fabrication of Meter-Scale Laser Resistant Mirrors for the National Ignition Facility, a Fusion Laser
}

C. J. Stolz, C. L. Weinzapfel, A. L. Rigatti, J. B. Oliver, J. Taniguchi, R. P. Bevis and J. S. Rajasansi

SPIE's $48^{\text {th }}$ Annual Meeting AM300 Advances in Mirror Technology for X-ray, EUVL, Laser and Other Applications

San Diego, CA, August 3-8, 2003

U.S. Department of Energy

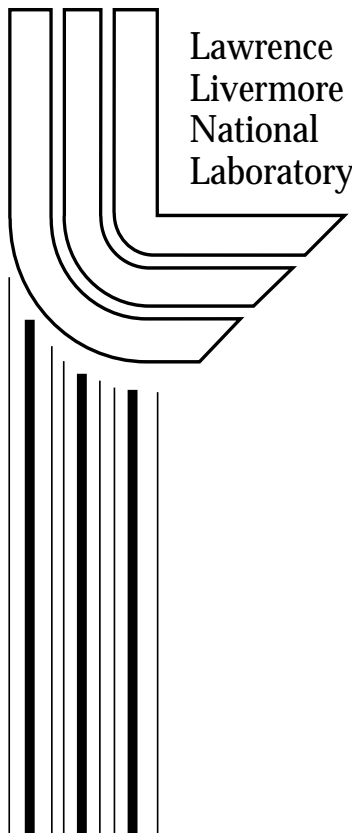

July 7, 2003 


\section{DISCLAIMER}

This document was prepared as an account of work sponsored by an agency of the United States Government. Neither the United States Government nor the University of California nor any of their employees, makes any warranty, express or implied, or assumes any legal liability or responsibility for the accuracy, completeness, or usefulness of any information, apparatus, product, or process disclosed, or represents that its use would not infringe privately owned rights. Reference herein to any specific commercial product, process, or service by trade name, trademark, manufacturer, or otherwise, does not necessarily constitute or imply its endorsement, recommendation, or favoring by the United States Government or the University of California. The views and opinions of authors expressed herein do not necessarily state or reflect those of the United States Government or the University of California, and shall not be used for advertising or product endorsement purposes.

This is a preprint of a paper intended for publication in a journal or proceedings. Since changes may be made before publication, this preprint is made available with the understanding that it will not be cited or reproduced without the permission of the author.

This report has been reproduced directly from the best available copy.

A vailable electronically at http:/ / www.doc.gov/ bridge

A vailable for a processing fee to U.S. Department of Energy

And its contractors in paper from

U.S. Department of Energy

Office of Scientific and Technical Information

P.O. Box 62

Oak Ridge, TN 37831-0062

Telephone: (865) 576-8401

Facsimile: (865) 576-5728

E-mail: reports@adonis.osti.gov

A vailable for the sale to the public from

U.S. Department of Commerce

National Technical Information Service

5285 Port Royal Road

Springfield, VA 22161

Telephone: (800) 553-6847

Facsimile: (703) 605-6900

E-mail: orders@ntis.fedworld.gov

Online ordering: http:/ / www.ntis.gov/ ordering.htm

OR

Lawrence Livermore N ational Laboratory

Technical Information Department's Digital Library

http:/ / www.Ilnl.gov/ tid/ Library.html 


\title{
Fabrication of meter-scale laser-resistant mirrors for the National Ignition Facility, a fusion laser
}

\author{
Christopher J. Stolz and Carolyn L. Weinzapfel \\ University of California, Lawrence Livermore National Laboratory \\ 7000 East Avenue L-491, Livermore, CA 94550 \\ Amy L. Rigatti, Jim B. Oliver, and Jason Taniguchi \\ University of Rochester, Laboratory for Laser Energetics, \\ 250 E. River Rd., Rochester NY 14623 \\ Ron P. Bevis and Jasbir S. Rajasansi \\ Spectra-Physics, Inc., 1330 Terra Bella Ave., Mountain View, CA 94043
}

\begin{abstract}
Large-aperture laser-resistant mirrors are required for the construction of the National Ignition Facility, a 1.8 MJ laser. In order to fabricate the 1408 mirrors, a development program was started in 1994 to improve coating quality, manufacturing rate, and lower unit cost. New technologies and metrology tools were scaled to meter size for facilitization in 1999 at Spectra-Physics and the Laboratory of Laser Energetics at the University of Rochester. Pilot production, to fabricate $5-10 \%$ of each component, commenced in 2001 and full production rates were achieved in 2002. Coating production will be completed in 2008 with the coating of $460 \mathrm{~m}^{2}$ of high-damage-threshold precision coatings on 100 tons of BK7 glass with yields exceeding $90 \%$.
\end{abstract}

Keywords: Mirrors, hafnia/silica multilayers, laser damage

\section{INTRODUCTION}

Currently lasers are the only technology available to generate the conditions necessary for controlled fusion ignition in a laboratory; temperatures $10 \times$ higher than our sun's core and densities $20 \times$ greater than lead. The National Ignition Facility (NIF) being constructed at Lawrence Livermore National Laboratory consists of a 192-beam nanosecond laser as the driver for fusion ignition. ${ }^{1}$ Damage resistant mirrors are a fundamental component for steering the $40-\mathrm{cm}$ laser beams, with minimal transport loss and wavefront deformation, into the 10-m diameter target chamber.

Electron-beam deposited coatings are the most widely researched deposition technique for laser damage resistance at $1053 \mathrm{~nm}$ in the nano-scale pulse length regime. ${ }^{2}$ Consequently, the most laser resistant coatings are E-beam coatings at these conditions. This process is scalable to 1-meter aperture optics, as illustrated in figure 1, so is an appropriate choice for manufacturing fusion laser mirrors. The major disadvantages of E-beam coatings are scatter and humidity-related spectral and stress shifts as a result of the columnar microstructure of the films. However, for this application, the reflection required $(\mathrm{R}>99.5 \%)$ can be readily achieved. Tuning the process parameters for operation in the specific environment can also compensate for the environmentally-dependent spectral and stress shifts. ${ }^{3}$ 

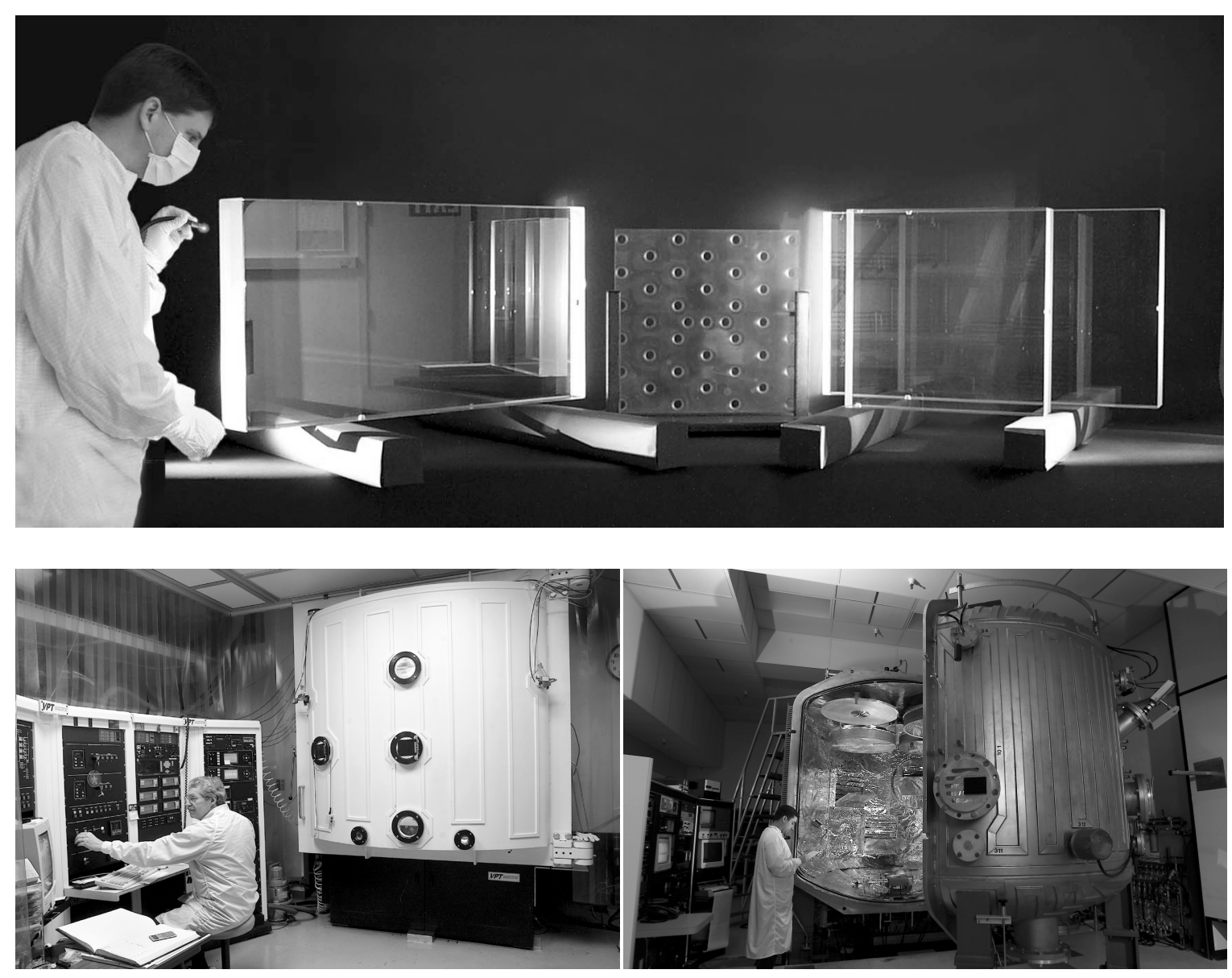

Fig. 1 Cavity mirror and polarizer optics for the NIF laser (top image). Deposition systems (1-r) at LLE and S-P used to fabricate NIF optics up to 1 meter in size (bottom images).

\section{SCHEDULE}

Mirror fabrication is divided into three fundamental stages. The first step is melting, annealing, and rough shaping of the raw blank material. The blanks are then shaped, ground, and figured as substrates. Finally the multilayer optical coating is deposited. These three manufacturing steps occur at different vendors. A development program was started in 1995 in order to increase the monthly fabrication rate by $2-5 \times$ and to improve optic quality. After the new processes were determined, the vendors were facilitized with full-scale equipment. Each of the vendors had different facilitization and development needs. Finally the new manufacturing processes were optimized during pilot production when $5-10 \%$ of the total number of optics were manufactured. All of the mirror vendors are now in full production with completion expected in 2007. Figure 2 illustrates the different program phases for each of the three manufacturing steps.

The glass blanks were all poured from continuous melters and did not require any development since little cost savings would be realized over the current start-of-the-art technology. A significant investment $(\sim 34 \mathrm{M})$ occurred at the finishing and coating vendors to develop, facilitize, and implement the new processes into a robust manufacturing process. The emphasis of the development effort was on improving the determinism of the fabrication process through improved monitoring and improved process stabilization. ${ }^{4-5}$ 


\section{LASER DAMAGE}

The fluence requirements for NIF transport mirrors are 2-3× higher than NOVA, the previous fusion laser at LLNL. In order to achieve this increase in laser resistance, a significant development program was funded. Two major changes were instituted as a result of this development. 1) Coatings are now laser conditioned to benignly eject micron-sized coating defects. ${ }^{6-7}$ The nodular ejection pits that remain are stable at the required fluence and do not impact the laser performance. ${ }^{8}$ 2) Coatings are now deposited from hafnium metal (Hf) and silica $\left(\mathrm{SiO}_{2}\right){ }^{9}{ }^{9}$ This material composition is the most optimum solution for laser-resistant mirrors and the metallic starting material decreases defect density and increases interfacial quality.

\subsection{Laser conditioning}

Laser conditioning is the process where the mirror surface is irradiated at low fluence and then ramped in fluence until the mirror has been exposed to the peak operating fluence. ${ }^{10}$ The laser resistance has been shown to increase by a factor of two or more by this post-processing step. The images in figure 3 show the equipment used on the mirrors for the laser conditioning process.
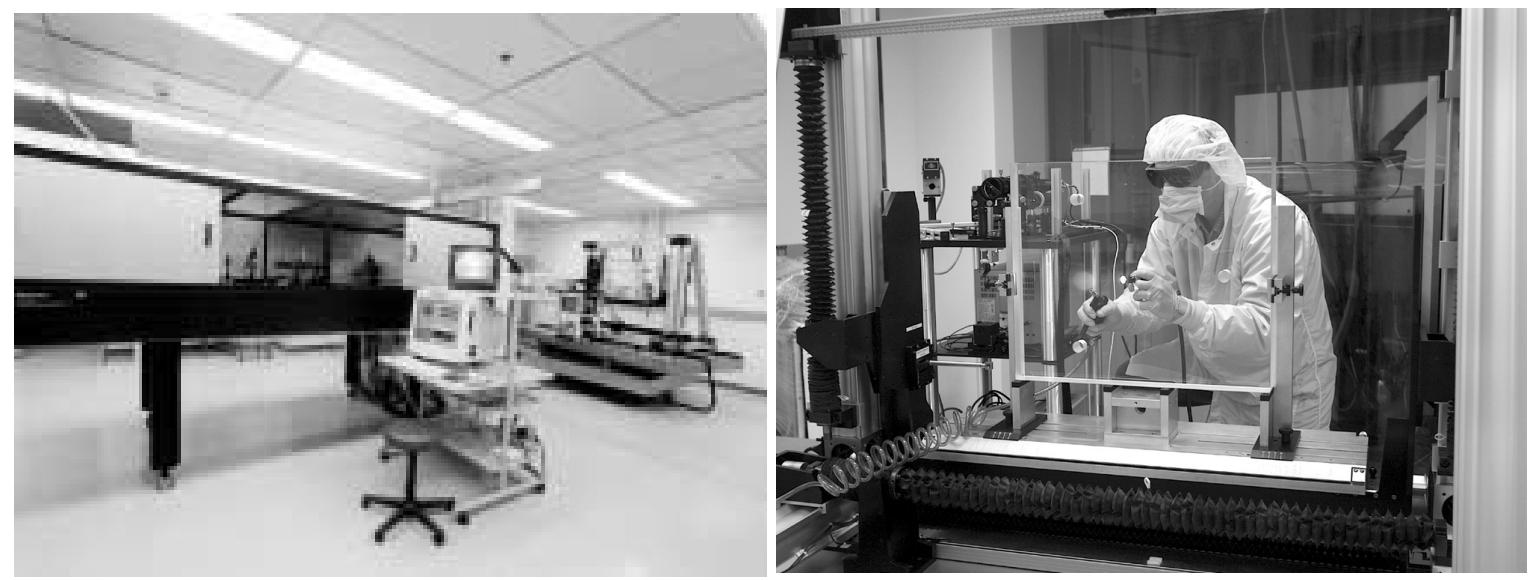

Fig. 3 Raster-scan based laser conditioning station used to double the laser resistance of NIF mirrors and verify that the mirrors will meet the operating fluence over the entire aperture.

Previous research has shown that nodule ejection is one of the mechanisms that lead to the increase of laser resistance of a coating as a result of the laser conditioning process. ${ }^{6}$ When the defect is ejected at a low enough fluence, the extent of the collateral damage created is minimized. When done properly, a very smooth pit remains that is stable above the peak operating fluence of the laser. If the defect is ejected at too high of a fluence, significant collateral damage is created and the nodule ejection pit becomes unstable and grows at fluences below the peak operating fluence of the laser.

There are two methods of accomplishing this process. ${ }^{10}$ Coatings can be on-line conditioned, by installing the mirrors into the main laser and gently ramping the fluence. An alternative method is off-line conditioning where the optic is conditioned on a sub-aperture workstation. The mirror is raster scanned across the beam to expose the entire surface. For large NIF mirrors, a typical off-line conditioning scan can take up to 20 hours. A higher fluence is then set and the mirror is raster scanned again. This process is repeated until the desired maximum fluence is achieved. 
The starting and increment fluence between shots has been optimized experimentally. During development, a 6-step process was initially used. The starting fluence was $50 \%$ of the unconditioned damage threshold. The fluence increment was defined as the difference of the final and starting fluence divided by the 6 steps for a constant fluence ramp.

Today's mirrors are off-line laser conditioned by a 2-step process. The starting fluence is $21 \mathrm{~J} / \mathrm{cm}^{2}$ with a $10 \mathrm{~ns}$ pulse length using $1064 \mathrm{~nm}$ Q-switched lasers from Spectra Physics. During the nodule ejection process a plasma is created. Hafnia and silica multilayer mirrors generally have very few plasmas created when raster scanned below this starting fluence. Additionally, most surface contamination such as dust is removed with little modification to the mirror at this starting fluence. The final fluence is $27 \mathrm{~J} / \mathrm{cm}^{2}$ also at a $10 \mathrm{~ns}$ pulse length. The conditioning laser has a Gaussian spatial profile. The optic is translated between pulses by the $90 \%$ intensity beam diameter. Since the mirror translation is a fraction of the total beam diameter, the Gaussian shape also creates a fluence ramp for more "gentle" conditioning. A small percentage of the NIF beam operates above the final fluence, therefore the final conditioning will be done on-line during normal operations in the areas where the mirror is exposed to higher fluences.

There are a number of advantages to off-line laser conditioning. Perhaps the most significant advantage is that in addition to increasing the laser resistance of the coating, the entire surface is damage tested. This gives the coating vendor immediate feedback about their deposition process. If laser damage occurs, then three $1 \mathrm{~cm}^{2}$ scans are performed on the site. If the site remains stable, then the optic is accepted. Damage greater than $1 \mathrm{~mm}$ in diameter is cause for the optic to be rejected. Damage spots smaller than this have very little impact on the performance of the main laser. A histogram of the largest defect/damage size after laser conditioning is reported in figure 4 . With the completion of greater than $25 \%$ of the NIF transport mirrors, only one has been rejected for laser damage.

Before laser conditioning of the mirrors, the laser resistance of the coating run is measured on a 50-mm diameter coating witness to test for significant run anomalies such as high absorption or high particulate densities due to source spitting when a void is exposed. A $1-\mathrm{cm}^{2}$ area of the sample is tested with the same raster-scan parameters used during laser conditioning of the large optics. This same area is irradiated at increasing fluence until damage sites larger than $40 \mu \mathrm{m}$ are detected. If a low damage threshold is measured or an anomaly occurs during the coating run, then a lower starting fluence and/or additional steps may be added to the conditioning process to realize a gentler conditioning routine.

The correlation between damage thresholds measured over $1 \mathrm{~cm}^{2}$ and up to $3,000 \mathrm{~cm}^{2}$ can be very poor because each defect has a different damage threshold. Therefore, rare low-threshold defects have a significantly lower percentage of occurrence over small areas. Also the damage size criteria is different between the $50-\mathrm{mm}$ aperture $(40 \mu \mathrm{m})$ and the fullaperture $(1000 \mu \mathrm{m})$ tests.

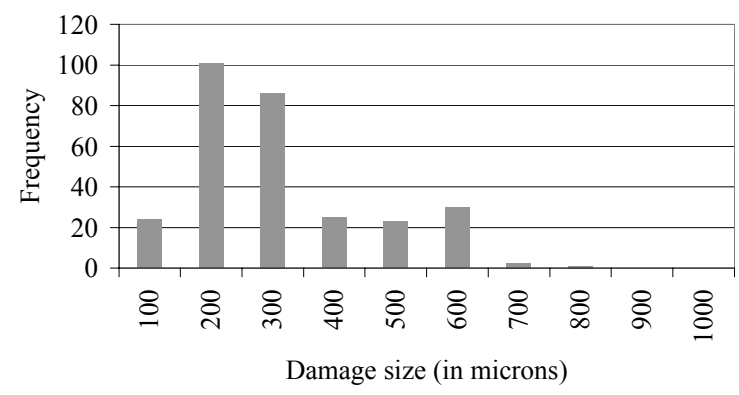

Fig. 4 Histogram of damage size of mirrors conditioned to $18 \mathrm{~J} / \mathrm{cm}^{2}$ at $1064 \mathrm{~nm}$ scaled to a 3 -ns pulse length.

\subsection{Hafnia \& Silica materials}

Hafnia and silica multilayer mirrors were first used on the NOVA laser during operations in the early 1990's on replacement optics. ${ }^{11}$ These mirrors were deposited using hafnia $\left(\mathrm{HfO}_{2}\right)$ as the starting material. Hafnia silica multilayer mirrors were used exclusively on Beamlet, the single-beam prototype of the NIF laser. ${ }^{12}$ Mirrors deposited from 
hafnium (Hf) were first manufactured for the majority of the mirrors on the Omega laser at the Laboratory for Laser Energetics also during the early 1990 's ${ }^{13}$ and for the high-fluence mirrors on Beamlet.

During NIF development experiements the coating defect density was reduced 3-10× when using Hafnium (Hf) as the starting material. The higher thermal conductivity of the metallic form of Hafnium (Hf) causes a more densely packed plug in the E-gun crucible. The absence of entrapped gas pockets minimizes particle ejection from the source which becomes incorporated into the multilayer coating. Also, the metallic form is homogeneous, without volumetric-induced stresses developed in the oxide due to phase transformations between the molten surface and the edge of the plug in contact with the water-cooled crucible that holds the starting material. Finally coatings deposited from Hafnium (Hf) metal have better interfacial quality and hence are more resistant to interfacial laser damage. ${ }^{14}$ This is important because interfacial damage such as flat-bottom pits and delamination grow at significantly lower (2-10×) fluences than nodularejection pits. ${ }^{15}$

Attempts to deposit from silicon were less successful. ${ }^{7}$ Good stoichiometry could only be achieved by increasing the energy of the deposition process. Energetic deposition processes provide the benefit of small spectral shifts, however, damage resistance over large areas in the 3-ns pulse length regime tends to be poor due to the amount of collateral damage that occurs during nodular ejection. A new class of defects termed "splash" defects were observed and were believed to consist of substoichiometric $\mathrm{SiO}_{\mathrm{x}}$. Finally heavy spitting of the silicon source was observed which was believed to have been responsible for high particle densities in the multilayer coatings.

\section{SPECTRAL}

One mirror from each coating run is measured on a reflectometer or photometer as illustrated in figure 5 to determine compliance to the spectral requirements. Fullaperture measurements are achieved on the photometer by raster-scanning the mirror past the laser beam. Measurements are done at use angle, wavelength, and polarization to validate performance against specification.

When depositing from hafnium (Hf) metal, the electron beam can be held stationary enabling a uniform and stable deposition plume. This enables improved thickness control as exemplified by the $2-3 \times$ improvement in measured yields for polarizers; an optic that is particularly sensitive to small thickness errors. An example of the current spectral performance of NIF mirrors are in the histograms in figure 6 .

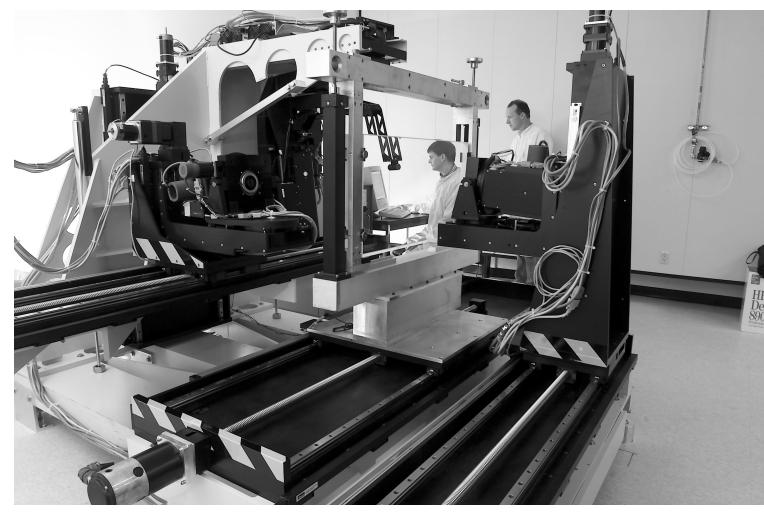

Fig. 5 Raster-scanning laser photometer used to measure full-aperture spectral characteristics of NIF mirrors.
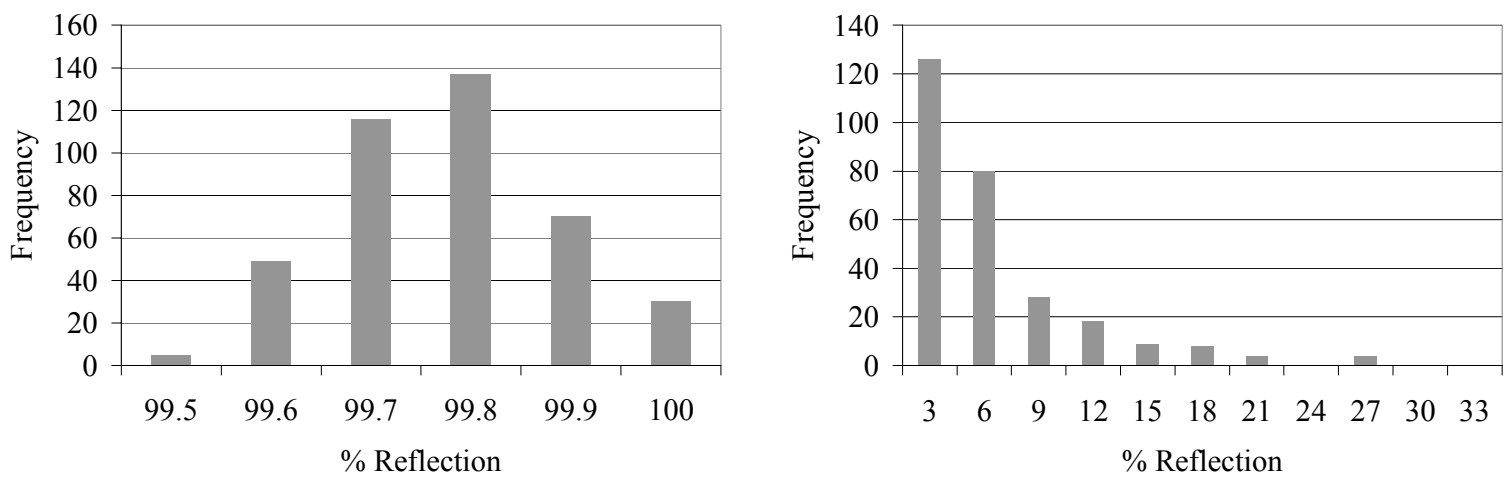

Fig. 6 Histograms of NIF mirror reflectance at $1053 \mathrm{~nm}$ (left image) and $351 \mathrm{~nm}$ (right image). 
The spectral requirements of the NIF transport mirrors are complex. Their primary function is efficient transport of the main 1053-nm high-fluence beam. High reflectance is also required at a low-fluence alignment laser wavelength of 375 $\mathrm{nm}$. This alignment laser is used for positioning the NIF laser beams onto the target. The NIF transport mirrors also have low reflectivity requirements at $351 \mathrm{~nm}$ and over the wavelength range of $400-700 \mathrm{~nm}$. Backscattered light from the target in these wavelength regions are rejected by the NIF transport mirrors to prevent damage to the front end of the NIF laser. A typical spectra of the NIF transport mirror is shown in figure 7.

The NIF transport mirrors have mounting holes cored into the rear surface of the substrates. This mounting scheme was adopted to minimize the amount of gravitationally-induced distortion to the mirror surfaces. Unfortunately, the intensity of the backscattered light is sufficient to damage the metallic mounting lugs. To overcome the opposite requirements of rejection of backscatter into the front end of NIF (low reflectivity at the backscatter wavelengths) and protection of the mounting lugs (low transmission at the backscatter wavelengths), the absorption of the mirror substrates is increased by solarization from exposure to Colbalt 60 Gamma Rays. ${ }^{16}$ Figure 8 illustrates the significant change in visual transparency of the mirror substrates by solarization. Laser damage studies at $1053 \mathrm{~nm}$ validated that Gamma Ray exposure does not degrade the laser resistance of multilayer mirror coatings as long as laser conditioning occurs before

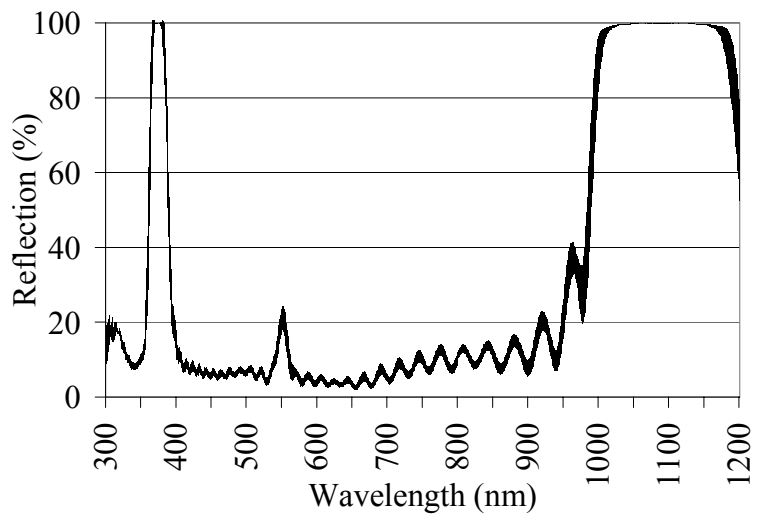

Fig. 7 Spectral characteristics of a NIF transport mirror. Line width is equivalent to the standard deviation $(1 \sigma)$ of the measured coating runs. solarization.

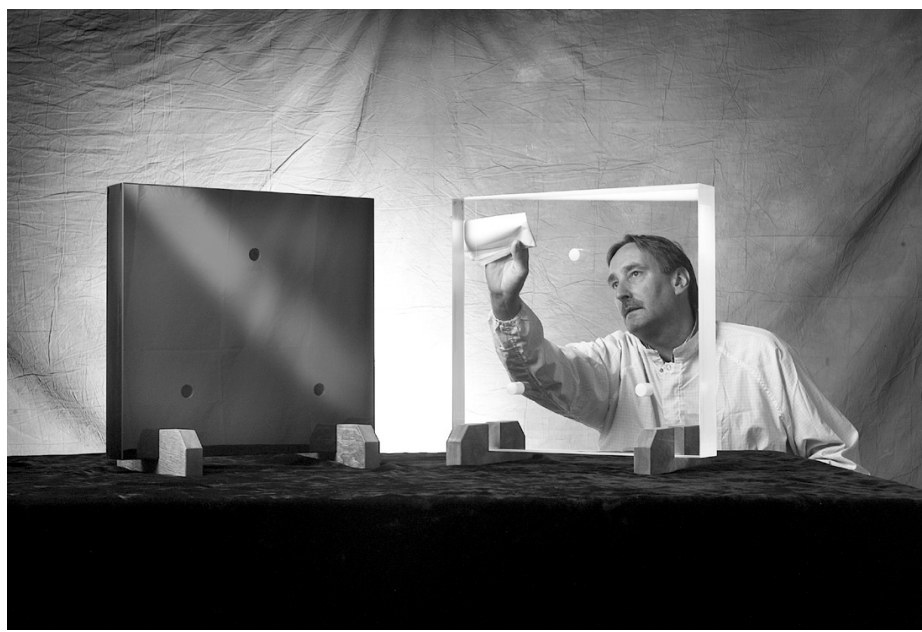

Fig. 8 Solarization darkens the bulk material (left optic) in NIF transport mirrors.

\section{WAVEFRONT}

The reflected wavefront of NIF transport mirrors is measured on an 18-inch phase-measuring interferometer with a wavelength of $1064 \mathrm{~nm}$ to eliminate the phase issues associated with interferometric measurements being made outside the reflection band of the coating. Figure 9 shows a typical interferometric set up. Histograms of the reflected wavefront are also illustrated in figure 9. 

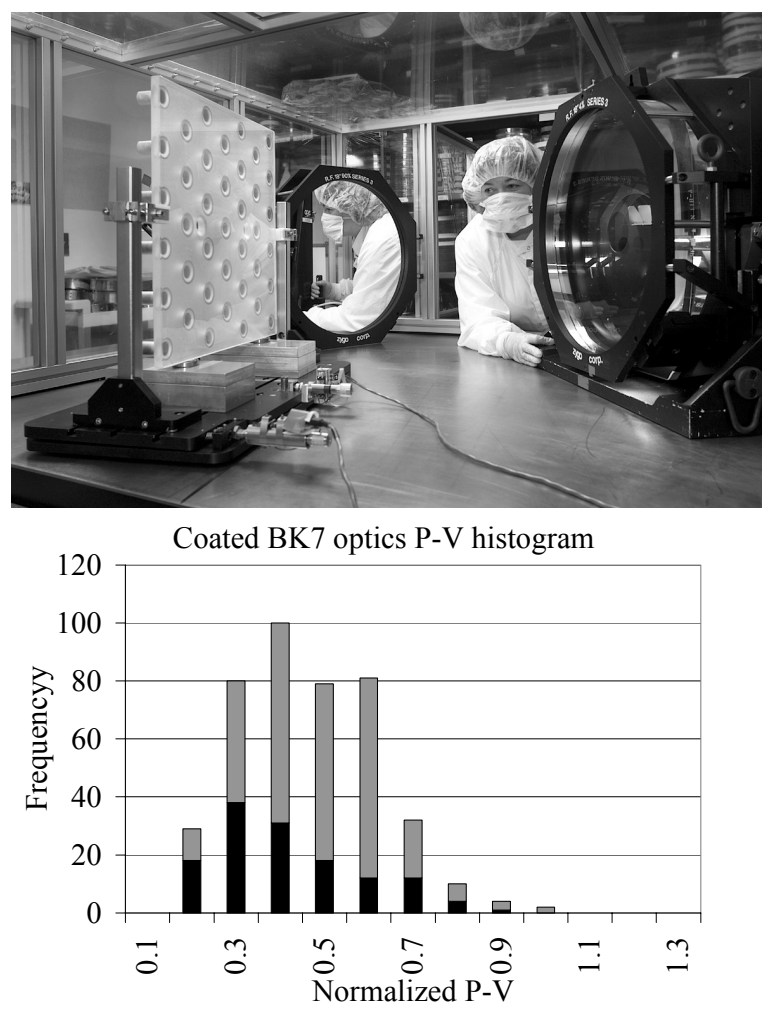

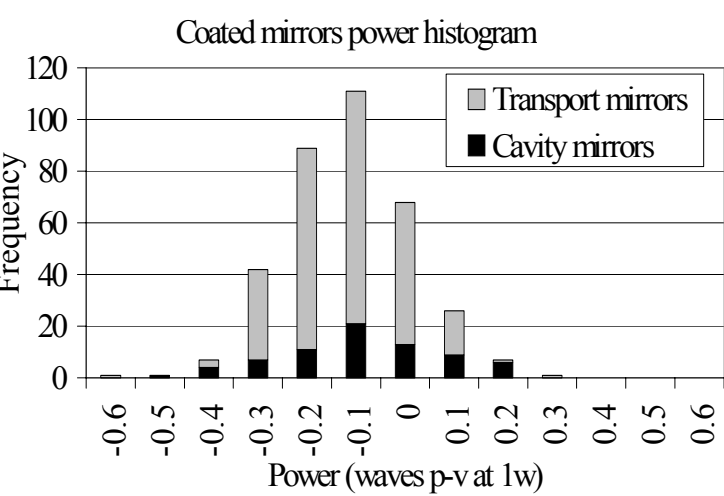

Coated mirrors RMS gradient histogram

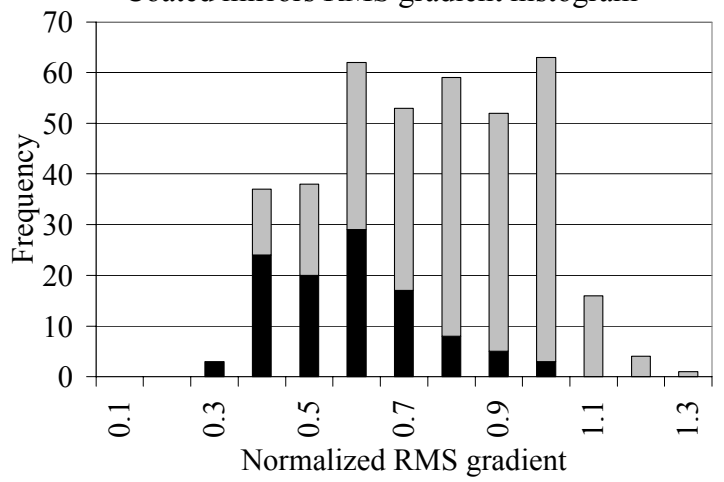

Fig. 9 Image of interferometric measurement of a deformable mirror (top left). Histogram of reflected wavefront; power (top right), P-V (bottom left), and RMS gradient (bottom right).

The NIF mirror reflected wavefront is affected by a number of factors. The cavity mirrors are used in a dry environment $(<2 \%$ relative humidity) and the transport mirrors are used in ambient conditions ( $40 \pm 6.5 \%$ relative humidity). Since electron-beam deposited coatings are sensitive to humidity, the proper deposition parameters are required to achieve low-stress coatings in their operational environment. By adjusting the oxygen backpressure during deposition of the silica layers, low-stress coatings can be manufactured for either low or moderate humidity levels. ${ }^{3}$

Coating stress also changes over time. In fact, the reflected wavefront of a NIF transport mirror can change by greater than 0.5 waves P-V at $1064 \mathrm{~nm} 30$ days after deposition. The coating stress stabilizes over a month so the NIF transport mirrors are "aged" before final interferometric measurements.

Occasionally unpredictable changes in reflected wavefront are observed in NIF transport mirrors after deposition. Studies of the impact of thermal cycling under the same conditions used during coating deposition on uncoated finished substrates demonstrate a non-deterministic variation in reflected wavefront. These changes are low-order aberrations (power and astigmatism). Some substrates do not change after thermal cycling while others can change by up to 0.5 waves P-V convex at $1064 \mathrm{~nm}$. The cause of this phenomenon is not well understood and unfortunately, although thermal cycling dampens reflected wavefront changes on subsequent thermal cycles, it is not completely diminished.

The solution adopted for this problem was to compensate for the additional wavefront power in the NIF laser beam by translating lenses to recollimate the beams or focus the beam on the target. Deformable mirror stroke was also budgeted to correct some of the beam distortion caused by the mirrors within the multi-pass cavity section of the laser. These transient thermal effects remain an area of active study. 


\section{SUMMARY}

The fabrication of these meter-scale laser resistant coatings is a fundamental aspect of the beam steering needed to direct the laser beams into the target chamber to achieve the necessary conditions for a fusion reaction or to collect experimental data for the stockpile stewardship program. A successful program of development, facilitization, and process optimization during pilot production has enabled a 2-5× increase in the monthly fabrication rate of optics of this quality. Completion of the mirrors will occur in 2007 to allow completion of the NIF laser facility in 2008.

\section{AKNOWLEDGEMENTS}

The authors would like to acknowledge the support of Andrea Flammini in preparing this manuscript. The authors would also like to acknowledge the damage testing, reflected wavefront measurements, and spectral characterization performed by Fred San Agustin and Natasha Chuyanova at S-P and Nelson LeBarron and Hope D'Alessandro at LLE. This work was performed under the auspices of the U. S. Department of Energy by the University of California, Lawrence Livermore National Laboratory under Contract No. W-7405-Eng-48.

\section{REFERENCES}

1. E. I. Moses, J. H. Campbell, C. J. Stolz, and C. R. Wuest, "The National Ignition Facility: the world's largest optics and laser system," Photonics West 2003: High-Power Lasers and Applications, SPIE proceedings, to be published.

2. C. J. Stolz and F. Y. Genin "Laser resistant coatings", in Optical Interference Coatings in Springer Series in Optical Sciences, Eds. N. Kaiser and H. Pulker, 309-333, Springer-Verlag, Berlin Heidelberg, , 2003.

3. J. F. Anzellotti, D. J. Smith, R. J. Sczupak, and Z. R. Chrzan, "Stress and environmental shift characteristics of $\mathrm{HfO}_{2} / \mathrm{SiO}_{2}$ multilayer coatings," in Laser-Induced Damage in Optical Materials: 1996, H. E. Bennett, A. H. Guenther, M. R. Kozlowski, B. E. Newnam, and M. J. Soileau, eds., SPIE 2966, 258-264 (1997).

4. C. J. Stolz, J. A. Menapace, M. R. Borden, A. Slomba, C. Kiikka, and S. Gelman, "Status of optical finishing for the National Ignition Facility," in Optical Fabrication and Testing, OSA Technical Digest, 67-69 (2002).

5. T.G. Parham, C. J. Stolz, T. Baisden, M. R. Kozlowski, C. Kiikka, and D. M. Aikens, "Developing optics finishing technologies for the National Ignition Facility," ICF Quarterly Report 9, LLNL Report UCRL-LR-105821-99-20, 177-191 (1999).

6. A. Fornier, C. Cordillot, D. Ausserre, and F. Paris, "Laser conditioning of optical coatings: some issues in the characterization by atomic force microscopy", in Laser-Induced Damage in Optical Materials: 1993, H. E. Bennett, L. L. Chase, A. H. Guenther, B. E. Newnam, and M. J. Soileau, eds., Proc. Soc. Photo-Opt. Instrum. Eng. 2114, 355-365 (1994).

7. A. B. Papandrew, C. J. Stolz, Z. L. Wu, G. E. Loomis, and S. Falabella, "Laser conditioning characterization and damage threshold prediction of hafnia/silica multilayer mirrors by photothermal microscopy," in Laser-Induced Damage in Optical Materials: 2000, G. J. Exarhos, A. H. Guenther, M. R. Kozlowski, K. L. Lewis, and M. J. Soileau, eds., Proc. SPIE 4347, 53-61, (2001).

8. M. C. Staggs, M. Balooch, M. R. Kozlowski, and W. J. Siekhaus, "In-situ atomic force microscopy of laserconditioned and laser-damaged $\mathrm{HfO}_{2} / \mathrm{SiO}_{2}$ dielectric mirror coatings," in Laser-Induced Damage in Optical Materials: 1991, H. E. Bennett, L. L. Chase, A. H. Guenther, B. E. Newnam, and M. J. Soileau, eds., Proc. Soc. Photo-Opt. Instrum. Eng. 1624, 375-385 (1992).

9. C. J. Stolz, L. M. Sheehan, M. K. Von Gunten, R. P. Bevis, and D. J. Smith, "The advantages of evaporation of hafnium in a reactive environment to manufacture high damage threshold multilayer coatings by electron-beam deposition", in Advances in Optical Interference Coatings, C. Amra and H. A. Macleod, eds., Proc. Soc. Photo-Opt. Instrum. Eng. 3738, 318-324 (1999).

10. C. J. Stolz, L. M. Sheehan, S. M. Maricle, S. Schwartz, and J. Hue, "A study of laser conditioning methods of hafnia silica multiplayer mirrors," in Laser-Induced Damage in Optical Materials: 1998, G. J. Exarhos, A. H. Guenther, M. R. Kozlowski, K. L. Lewis, and M. J. Soileau, eds., SPIE 3578, 144-152 (1999). 
11. M. R. Kozlowski, C. R. Wolfe, M. C. Staggs, and J. H. Campbell, "Large area laser conditioning of dielectric thin film mirrors," in Laser-Induced Damage in Optical Materials: 1989, H. E. Bennett, L. L. Chase, A. H. Guenther, B. E. Newnam, and M. J. Soileau, eds., Proc. Soc. Photo-Opt. Instrum. Eng. 1438, 376-390 (1989).

12. B. Van Wonterghem, J. R., Murray, J. H. Campbell, D. R. Speck, C. Barker, I. Smith, D. Browning, and W. Behrendt, "Performance of a prototype, large-aperture multipass Nd-glass laser for inertial confinement fusion", Appl. Opt. 36, 4932-4953 (1997).

13. D. J. Smith, J. F. Anzellotti, A. W. Schmid, S. Papernov, Z. R. Chrzan, and S. J. Van Kerkhove, Damage fluence at $1054 \mathrm{~nm}$ and $351 \mathrm{~nm}$ of coatings made with hafnium oxide evaporated from metallic hafnium," in Laser-Induced Damage in Optical Materials: 1994, H. E. Bennett, L. L. Chase, A. H. Guenther, B. E. Newnam, and M. J. Soileau, eds., Proc. Soc. Photo-Opt. Instrum. Eng. 2428, 319 (1995).

14. S. C. Weakley, C. J. Stolz, Z. L. Wu, R. P. Bevis, and M. K. Von Gunten, "Role of starting material composition in interfacial damage morphology of hafnia silica multilayer coatings," in Laser-Induced Damage in Optical Materials: 1998, G. J. Exarhos, A. H. Guenther, M. R. Kozlowski, K. L. Lewis, and M. J. Soileau, eds., Proc. SPIE 3578, 137-143, (1999).

15. F. Y. Génin, C. J. Stolz, and M. R. Kozlowski, "Growth of laser-induced damage during repetitive illumination of $\mathrm{HfO}_{2}-\mathrm{SiO}_{2}$ multilayer mirror and polarizer coatings," in Laser-Induced Damage in Optical Materials: 1996, H. E. Bennett, A. H. Guenther, M. R. Kozlowski, B. E. Newnam, and M. J. Soileau, eds., SPIE 2966, 273-282 (1997).

16. C. J. Stolz, J. A. Menapace, F. Y. Génin, P. R. Ehrmann, P. E. Miller, P. E., and G. T. Rogowski, "Influence of BK7 substrate solarization on the performance of hafnia and silica multilayer mirrors," in Laser-Induced Damage in Optical Materials: 2002, G. J. Exarhos, A. H. Guenther, M. R. Kozlowski, K. L. Lewis, M. J. Soileau, and C. J. Stolz, eds., SPIE 4932, 38-47, (2003). 